\title{
A ARGUMENTAÇÃO POLÍTICA DE OCKHAM A FAVOR DO PRIMADO DE PEDRO CONTRÁRIA À TESE DE MARSÍLIO DE PÁDUA
}

José Antônio de C. R. de Souza*

SINTESE - Marsilio de Pádua e Guilherme de Ockham viveram seus últimos anos na corte de Luís da Baviera. Ambos opuseram-se aos papas da época. Entretanto, a posição deles a respeito do primado do sumo pontífice não é idêntica. Enquanto Marsilio a nega quase totalmente, Ockham observa que se trata de um problema de cunho teológico e critica os argumentos de Marsilio.

\begin{abstract}
During the last years of their lives, Marsilius of Padua and William of Ockham lived at the court of Louis IV (the Bavarian). Both have acted against the popes of the epoch. But their position on the primate of the Pontifex Maximus isn't identical. While Marsilius dernies it almost in the whole, Ockham asserts that the primate is a theological question and criticizes Marcilius' arguments.
\end{abstract}

Há algum tempo, os veículos de comunicação internacionais, com base no agravamento do estado de saúde do Santo Padre, e igualmente no que estipula o Código de Direito Canônico, quanto à resignação dos bispos ao governo de suas dioceses, completando 75 anos de idade, vinham especulando acerca duma provável renúncia de João Paulo II (1978- ) ao sumo pontificado.

O Romano Pontífice, no entanto, à véspera de completar 75 anos, em 18 de maio passado, declarou na audiência pública das quartas feiras, que só deixaria 0 trono de Pedro morto.

Essa afirmação categórica, se de um lado pôs fim às mencionadas especulações, das quais a mais importante subrepticiamente insinuada, era se um Papa pode renunciar o governo da Igreja, de outro, nos levou a pensar novamente sobre a autoridade do papa, no que respeita ao seu fundamento primeiro, e ainda acerca de seu papel singular à frente da Igreja no mundo, instituição essa, cujo regime, monárquico-eletivo, perdura há quase dois mil anos.

As questões acima referidas não são novidade deste final do século XX. Foram, aliás, objeto de reflexão e debate nos últimos séculos da Idade Média, da par-

* Universidade Federal de Goiás - UFG - Goiânia. 
te de muitos pensadores daquela época, em vista de fatos concretos que ocorreram naqueles dias, tais como: a renúncia de Celestino V (1294), as teorias políticas antihierocratas, as teorias políticas conciliaristas, o Cisma do Ocidente (1378), a prática conciliarista (1414-1417) etc.

Nosso objetivo neste trabalho é revisitar em seu contexto próprio, o da Sociedade Cristã Medieval do século XIV, o debate ocorrido entre Marsilio de Pádua (1280-1342) e Guilherme de Ockham (1285-1349), acerca da commissio Petri ou do Primado de Pedro, certamente muito mais palpitante naqueles dias do que em nossa época, sob o ponto de vista político, em face das relações entre os poderes espiritual e temporal, dada a amplitude da autoridade que o Papa então exercia.

Naquela época, o maior adversário do primado papal foi Marsílio de Pádua. Ele e Guilherme de Ockham, conquanto tenham vivido a última fase de suas vidas na corte do Imperador Ludovico IV (1314-1347), em Munique, participando através de seus escritos do útlimo grande conflito entre o Papado e o Império, nem sempre compartilharam das mesmas idéias. ${ }^{1}$

Mas neste trabalho iremos apenas analisar os argumentos políticos apresentados por Ockham com referência à questão principal, considerando que uma reflexão que tentasse esgotar amplamente as teorias apresentadas por estes dois pensadores no tocante à mesma, em vista de sua relevância e da quantidade de páginas escritas a respeito, iria ocupar muito espaço neste volume. ${ }^{2}$

Ademais, temos em mente ainda que este assunto fundamenta-se essencialmente num dado proposto pela Revelação. Por isso mesmo, chamamos a atenção do leitor para o fato de que os argumentos apresentados por ambos, em geral, se respaldaram no Novo Testamento, nos comentários dos Padres da Igreja às passagens alusivas ao Primado, ora pinçadas nas Glosas, ora no Decreto, e nos Seis Livros das Decretais, (e tal foi o procedimento de Ockham), entretanto, Marsílio não usou esses Livros, senão para contestar sua legalidade e legitimidade, dado que os canonistas-hierocratas lançaram mão de muitas passagens que se encontram nos mesmos, para elaborar a teoria que atribuía ao Romano Pontífice a plenitudo potestatis in saecularibus et spiritualibus.

1 Não trataremos aqui dos motivos, e foram vários de ordem diversa, que levaram os dois pensadores a terem pontos de vista diferente sobre inúmeras questöes eclesiológico-políticas. Interessa ressaltar apenas que LEON BAUDRY em seu clássico trabalho sobre o Venerabilis Inceptor, publicado há quarenta e cinco anos, intitulado Guillaume d' Occam, Sa Vie, Ses Oeuvres, Ses Idées Sociales et Politiques, Tome I, Paris, Vrin, 1950, aludindo especialmente ao teor da II Parte do Dialogus, ressaltava que ai se encontram as críticas mais relevantes do Menorita Inglês ao Paduano, indicando genericamente os assuntos tratados e os locais em que se encontram no Defensor da Paz.

2 Alguns estudiosos recentemente se dedicaram a examinar em detalhes este assunto. Entre eles merecem destaque, G. LAGARDE, La Naissance de l'Esprit Laïque au Déclin du Moyen-Age, vol. V, Louvain-Paris, B. Nauwelaerts, 1963: 87-127; B. TERNEY, "From Thomas of York to William of Ockham The Franciscan and the Papal "Sollicitudo Omnium Ecclesiarum" 1250-1350, Communio 13 (1972): 607-658; A. S. McGRADE The Political Thought of William of Ockham Personal and Institutional Principles, Cambridge, CUP, 1974: 149-172; MARINO DAMIATA, Guglielmo d' Ockham: Povertà e Potere, vol. II, Firenze, ed. Studi Francescani, 1979: 163-185/412-415. 
Outrossim, sabemos que o Princeps Nominalium reivindicou para o teólogo a competência exclusiva para discutir temas dessa espécie, ${ }^{3}$ certamente defendendo essa posição, tanto contra os canonistas, quanto, acreditamos nós, contra os leigos que se metiam a escrever sobre Teologia, sem um razoável preparo, e tal era o caso do próprio Paduano.

O tema que nos propusemos tratar é abordado longamente pelo franciscano inglês, na III Parte do Dialogus, tratado I, Livro IV, ${ }^{4}$ o qual possui 26 capitulos de tamanho variado.

Este Livro IV é um corolário dos três imediatamente anteriores, os quais jogam uma luz sobre a tese que Ockham professava, dado que neles são discutidas ampla e detalhadamente, por exemplo, qual é a causa eficiente, qual a natureza, quais são a extensão e os limites do poder espiritual, e por via de conseqüência, se o

3 Breviloquio, ed. LUIS ALBERTO DE BONI, Petrópolis, Vozes, 1988, Livro I, capitulo V: 37: "Que poder, quanto, em que casos e sobre quem o papa possui, por direito divino e concedido só por Cristo, compete principalmente aos teólogos investigar, näo a outros, a não ser na medida em que säo levados a tomar algo da teologia. Como confirma Agostinho (Super Joh; cf c. 1, d.8, Quo iure): "O direito divino nós o temos nas Sagradas Escrituras [...]".

4 Os 26 capítulos desse livro e tratado do Dialogus III, foram publicados na volumosa edição de M. Goldast, intitulada Monarchia Sancti Romani Imperii, vol. II, Hanoviae, 1614. Estendem-se da página 846 à pág. 868 . Repare o leitor, outrossim, que a numeração das últimas duas páginas desse Livro IV estão erradas, saltando magicamente da 866 para a 988 (867), e depois, para 889 (868). Usamos a predita edição.

Esclarecemos, porém, que este assunto foi tratado por Ockham, pela primeira vez, em 1334, Dialogus I, V, XIV-XXI, publicado na edição supra referida.

Os mencinados 26 capítulos tratam sucintamente do seguinte: No primeiro e segundo, Venerabilis Inceptor expôs os principais argumentos arrolados por Marsílio de Pádua anti-primado petrino. No terceiro, o Mestre, atendendo a uma solicitação do discipulo, introduz "[...] uma outra opinião, segundo a qual Cristo estabeleceu o bem-aventurado Pedro líder, principe e prelado sobre os demais Apóstolos, e que ele foi-lhes superior, o que pode ser comprovado de muitos modos. Na verdade, isto pode ser demonstrado mediante as palavras de Cristo que se encontram no Evangelho de João, último capítulo, em que Ele se dirigindo pessoalmente a Pedro disse: "Apascenta as minhas ovelhas, apascenta os meus cordeiros" (Cfr. Dialogus, ed. cit., III, I, IV : 848). Essa é a crença e a tese do Venerabilis Inceptor que ele irá demonstrar até o capitulo undécimo (páginas 850-858).

Nesses capítulos, o Venerabilis Inceptor também expōe, redargue outros passos do Defensor da Paz, contrários ao ponto de vista que sustenta (cfr. Defensor da Paz, II, XXVIII, § § 5 e 6.

A exegese correta dos célebres versículos do Evangelho de Mateus (XVI, 16-19), "Tu es Petrus", respaldada em argumentos de autoridade, é apresentada pelo Menorita Inglês do capítulo XII ao XX (páginas 859-864). Por sinal, no capitulo XII, aproveita novamente da ocasiảo para inserir quase ad litteram outros passos do Defensor da $\mathrm{Paz}$, contrários à interpretação correta daqueles versiculos (cfr. II, XXVIII, § § 5 e 6 . Estamos a indicar essa obra de tal modo, porque utilizamos nossos originais em vernáculo, ainda não paginados, que deverá proximamente ser publicada pela Vozes.

Nos capitulos XVII e XIX, particularmente neste último, refuta outros argumentos contrários à sua tese, citando novamente outros passos do Defensor da Paz (Cfr. II, XXVIII, § § 5 e 6); no vigésimo, rebate ainda outras objeções apresentadas no capítulo XII, contra a tese que defende. No capitulo vigésimo primeiro, o Franciscano Inglês apresenta sua exegese relativa ao versículo de Lucas Ego autem rogavi pro te Petre (Cfr. Defensor da Paz II, XXVIII, § 7; II, XVI § 6.

Do capítulo XXII ao XXIV, Ockham, citando outras passagens de escritos dos Padres da Igreja que corroboram sua tese, reitera que esta sempre foi a crença da Igreja universal, ensinada desde a Era Apostólica até aquele momento, cujo magistério é infalivel (páginas 864-867). No capítulo XXV, - Venerabilis Inceptor refuta os últimos argumentos apresentados no capítulo primeiro, contrários à commissio Petri. Finalmente, no último capitulo, o Franciscano Inglês rapidamente discute uma questão acessória, a saber, se de fato Pedro exerceu ou não uma autoridade sobre os demais Apóstolos. 
Sumo Pontífice possui ou não a Plenitudo potestatis em ambas as esferas de poder; se possui ou não algum poder na esfera espiritual e se não possui poder nenhum (Marsílio de Pádua). Ainda são analisados comparativamente os regimes políticos e Ockham sugere, outrossim, qual é o melhor deles tanto para as sociedades civis quanto para a eclesiástica.

Feito este esclarecimento, ainda convém mencionar que Ockham analisou o tema em exame, respaldado nas seguintes outras fontes: a História Eclesiástica de Eusébio de Cesaréia, a Política de Aristóteles e a experiência.

Além dos motivos supraditos no início, outras razões nos levaram a abordar este assunto. Não podemos nos esquecer de que a Igreja Militante é uma sociedade inserida neste mundo e, como tal, precisa de um governo adequado à condição da vida presente.

O Primado Petrino foi igualmente o suporte mais importante para a teoria política medieval chamada hierocracia, cuja formulação mais sistematizada e consistente veio à luz justamente nos primeiros decênios do século XIV. ${ }^{5}$ Ora, Marsílio e Guilherme criticaram e questionaram duramente a legitimidade e legalidade da hierocracia, tal como a entendiam e justificavam os seus defensores. Qual teria sido, então, a posição adotada pelo Princeps Nominalium perante uma questão assaz delicada?

Como os demais assuntos discutidos no Dialogus, o que nos propusemos analisar é introduzido mediante uma quaestio, apresentada pelo discípulo ao mestre nos seguintes termos: "Por acaso, Cristo de fato teria estabelecido o bem-aventurado Pedro príncipe e prelado sobre os demais Apóstolos e sobre todos os fiéis? Acerca desta questão há várias opiniões a respeito, e quero que tu discorras sobre elas". ${ }^{6}$

Em seguida, o mestre passa imediatamente a discorrer acerca de uma das opiniões, segundo a qual, "[...] Cristo não estabeleceu o bem-aventurado Pedro principe e prelado sobre os demais Apóstolos e todos os fiéis [...]", ${ }^{7}$ apresentando uma série de argumentos teológicos ou de razão teológica que parecem fundamentá-la. É a doutrina de Marsílio de Pádua, a qual pode ser resumida nos seguintes pontos mais relevantes: 1) Todos os Apóstolos receberam os mesmos poderes. 2) São Paulo não recebeu seus poderes de Pedro e agiu como se fosse igual a ele. 3) O primado contradiz a ordem de Cristo proibindo aos seus Apóstolos de exercer qualquer tipo de autoridade. 4) Ele só pode ter sido atribuído a Pedro, mediante eleição dos outros Apóstolos ou através duma constituição imperial.

5 Tendo em vista os iniciantes no estudo das teorias politicas do tardo medievo, convém aludir ao menos sobre três teóricos da hierocracia, cujos textos estão publicados em Língua Portuguesa, nomeadamente, Egídio Romano e o seu Sobre o Poder Eclesiástico, ed. Luís Alberto De Boni, Petróplis, Vozes, 1989; Álvaro Pais e o Estado e Pranto da Igreja, 4 vols., por enquanto, ed. Miguel Pinto de Meneses, Lisboa, INIC, 1988/1994; Francisco de Meyronnes e a Quaestio de Subjectione, ed. José A. de Souza, in Lógica e Linguagem na Idade Média, Luis Alberto De Boni (org.), Porto Alegre, EDIPUCRS, 1995: 163-196. Os editores desses textos arrolam ampla bibliografia sobre essa concepção política do período.

6 Dialogus, III, I, IV, cap. I: 846.

7 É a tese principal de Marsilio de Pádua que se encontra enunciada, neste caso, no Defensor da Paz, II. capitulo XVI, § § $2,3,4,5,9$. 
Mas o primeiro argumento de natureza política apresentado por Ockham contra Marsílio encontra-se efetivamente no capítulo IV, do livro em questão, (página 850), em que ele analisa o versículo de João: "Pasce oves meas" [Jo. XXI, 17].

Com efeito, a interpretação que o Paduano deu ao mencionado versículo é, no mínimo, bem estranha e está completamente em desacordo com a experiência: como é possivel atribuir a todos os Apóstolos aquelas palavras que Cristo disse particularmente a Pedro, estabelecendo-o como pastor de todas as ovelhas e cordeiros ? Quando alguém, clérigo ou leigo, é nomeado para um cargo, por quem tem competência para tanto, essa pessoa o faz verbalmente ou por escrito, nominando-o explicitamente. Foi isso exatamente que ocorreu com Pedro, porque, caso contrário, a) ou cada um dos fiéis, mediante aquela frase dita por Cristo, teria sido constituído pastor da Igreja; b) ou então, por seu intermédio, excluídos os presbíteros, todos os Apóstolos, na pessoa de Pedro, teriam recebido uma determinada autoridade; c) ou então Pedro e os demais Apóstolos naquela ocasião teriam recebido uma autoridade para exercê-la sobre os demais presbiteros, dado esse que 0 adversário também não admite; ou ainda, que a mencionada autoridade não teria sido atribuída a todos os Apóstolos, uma vez que nem todos estavam presentes em tal oportunidade. ${ }^{8}$

$\mathrm{Na}$ verdade, a investidura de Pedro significa realmente que Cristo lhe concedeu não apenas a preeminência sobre todos os fiéis, incluindo entre eles os Apóstolos e os discipulos, sem estabelecer qualquer tipo de limite à sua autoridade, salvo o que estava expressamente proibido pela Lei Evangélica, mas também a missão de cuidar deles todos, nos aspectos espiritual e material. Ora, para o Apóstolo poder vir a desempenhar plenamente a sua missão, não era suficiente apenas a potestas ordinis ou sacramental, que todos os Apóstolos igualmente receberam do Senhor, graças à qual podiam anunciar a Boa Nova, batizar, perdoar os pecados, nem tampouco uma potestas iurisdictionis semelhante à deles, isto é, mais restrita.

Destarte, o ofício de Pedro exigia naturalmente que ela fosse muito mais ampla ou universal e com autoridade, para que os trabalhos apostólicos não fossem efe-

8 Dialogus, III, I, IV, cap. IV: 850: [...] Cristo ao proferir aquela frase dirigiu-se pessoalmente a Pedro e não aos demais Apóstolos. Demonstra-se primeiramente o argumento do seguinte modo: as palavras mediante as quais alguém é promovido a alguma dignidade ou oficio, são dirigidas àquele a quem são pessoalmente ditas, não na pessoa dos outros [...]. Noutras palavras, quando através de determinadas palavras alguém é designado para uma dignidade secular ou eclesiástica, todos os outros, particularmente aqueles de semelhante condição ou ménito, poderiam se considerar como investidos com mesma dignidade, de modo que se o Imperador, mediante tais palavras ou outras semelhantes, através de cartas ou de viva voz, declara, nomeio-te ou faço-te juiz, conde, duque ou advogado de tal região ou de tal cidade, todos os demais entenderiam que foram instituidos com a mesma dignidade. $\mathrm{E}$ assim, por razão semelhante, o mesmo procedimento deve ser aplicado no tocante à designação dos reitores, plebeanos e de quaisquer outros prelados da Igreja.

Ora, que ninguém possa ter dúvida de que tal opinião é um absurdo, logo se verá. De fato, mediante aquela frase [Pedro] foi investido na dignidade e no oficio pastoral, como, aliás, os mencionados adversários admitem, quando afirmam que Cristo o designou pastor de todos. Logo, aquelas palavras foram dirigidas pessoalmente ao bem-aventurado Pedro, não à pessoa de qualquer um dos outros. 851: quod ex privilegio conceditur uni, non intelligitur alii, etiam eiusdem conditionis et meriti esse concessum, nisi explicite hoc dicatur. 
tuados desordenadamente ou ao bel prazer de cada um. É exatamente isso que competia a Pedro, quer dizer, liderar os outros Apóstolos e os fiéis, mediante aquela frase dita por Cristo: "Pasce oves meas", ${ }^{9}$ e nisto consiste efetivamente a commissio Petri. ${ }^{10}$

Em seguida, Ockham, ao analisar igualmente os versículos que se encontram no Evangelho de Mateus (XVI, 16-19): "Tu es Petrus et super hanc petram aedificabo Ecclesiam meam et tibi dabo [...]", além de afirmar que Marsilio distorcia temerária e presunçosamente o significado real daquela passagem, ${ }^{11}$ dizendo, entre outras coisas, que só Cristo é o único fundamento da Igreja, e que Pedro não podia sê-lo, dado que era pecador e $\mathrm{O}$ tinha traído; que Ele, ao mudar o nome de Pedro, tencionava apenas ressaltar a sólida fé do Apóstolo, introduziu um outro argumento político, sustentando sua tese contra as invectivas do Paduano, ${ }^{12}$ alicerçadas neste caso específico no Livro das Retratações de Agostinho, em que o Bispo de Hipona alude ao fundamento da Igreja.

Trata-se da distinção entre fundamentum primarium et principale (capítulo XIX: 862) e fundamentum secundarium. O primeiro deles seguramente foi Cristo, sem o Qual a Igreja absolutamente não podia ter sido fundada. Ora, uma análise filosófico-política desta distinção nos mostra que Cristo é a causa eficiente da Igreja, enquanto outrora os Apóstolos - Pedro em particular, e hoje, seus sucessores e todos os batizados - são a causa agente da atuação da Igreja no mundo, porque o Senhor a tendo fundado, para os homens e de acordo com sua natureza, tinha que se adequar a essa realidade.

Essa nossa interpretação do mencionado passo de Ockham articula-se primeiramente com a seqüência de seu discurso e a análise que ofereceremos para 0 mesmo.

O Mestre Divino, ciente de que não podia ficar vivendo neste mundo para sempre, experiente e conhecendo a natureza humana, suas exigências e fragilidades, não quis deixar sua Igreja acéfala, por isso, deu-lhe o melhor governo possivel,

9 Dialogus, III, I, IV, cap. VIII, 855: "[...] nec aliquas oves excepit: ergo omnium ovium Israel fuit cura comissa beato Petro. Inter oves autem Israel precipue fuerunt apostoli", 852: "non distinxit inter oves has Christi et illas, ergo etiam super alios apostolos [...] constitutus fuit [...] Petrus; 853: auctoritatis docendi data fuit omnibus apostolis immediate a Christo; nec alii apostoli eam habuerunt a Petro, sed ex hoc non sequitur quod non fuerint inferiores Petro, omnes tamen subjecti rectori, vicario et pastori supremo, scilicet Petro". 855: "licet Christus dederit apostolis aliquam potestatem specialem, nunquam tamen concessit eis potestatem generalem vel aequalem potestatem Petri. Verbo generaliori usus est in praeficiendo Petrum, scilicet verbo pascendi: quod communis est quam verbum docendi, vel baptizandi, aut aliud tale. Quibus verbis usus est in concedendo potestatem in aliis apostolis [...]; non fuerunt exempti a potestate Petri, nisi quantum ad officium praedicationis, baptizandi, ligandi et solvendi a peccatis [...]" 857: "sed per verbum pascendi non solum importatur pascere alios verbo et exemplo, ac subsidio corporali: sed etiam potestative et cum auctoritate".

10 Dialogus, III, I, IV, cap. X, 857: "[...] commissio potestatis vel officii indefinite e simpliciter facta debet intelligi universaliter, ut scilicet omnia intelligantur esse concessa [...] quae non sunt prohibita; qui nihil excipit et potuit excipere, totum concessisse [...] videtur [...]".

11 Dialogus, III, I, IV, cap. XIII, 859: "sunt quidam, qui predicta opinantes [...] specialiter de temeritate et presumptione nituntur arguere; illa verba Christi sic debent intelligi, ut credatur per ipsa tunc primatus super omnes fideles fuisse Petro promissus". 
isto é, o regime monárquico, ${ }^{13}$ em perfeita consonância com a sua e presente condição, e a confiou a Pedro.

Essa decisão do Senhor tem importantes desdobramentos: 1) O poder de Pedro e de seus sucessores tem uma origem imediatamente divina, portanto, sua causa eficiente não é a mesma do poder secular, uma vez que este se efetiva imediatamente a partir do uso da razão e da vontade humanas. 2) Cristo ao dar à sua Igreja peregrina neste mundo um chefe visivel assumiu também uma atitude política, ao menos quanto à maneira como desejava que ela fosse governada, a fim de que seus dirigentes e membros, com maior ou menor responsabilidade, pudessem desempenhar bem a missão que Ele thes confiou.

Assim, aquele ato de Cristo não foi simplesmente arbitrário, ou fruto apenas de seu poder e vontade divinos, mas um gesto de Sua reta razão política, enquanto ser humano, ciente que estava de que os homens só se realizam em sociedade, e que esta necessita de dirigentes para alcançar os seus objetivos. A escolha de Pedro como líder da Igreja, por conseguinte, visava a que ela tivesse um dirigente investido com poderes tais que ao usá-los fosse capaz de prover as necessidades de todos os seus membros. Entretanto, se Cristo-Deus não fosse a causa eficiente da Igreja e não tivesse tido esta idéia a seu respeito, ela já teria há muito sossobrado, face às tempestades que a assolaram.

Em segundo lugar, conquanto Ockham não faça explicitamente referência alguma neste Livro IV, objeto de nossa análise, à origem e ao fundamento imediatos da autoridade secular, ${ }^{14}$ pensamos e entendemos que ele se apoiou comparativamente na teoria que formulou acerca da causa eficiente imediata do poder secular, para igualmente elaborar e explicitar mais um argumento político em favor da preeminência jurisdicional de Pedro e de seus sucessores. Notemos que não se trata de investigar quem é causa eficiente imediata que concede a autoridade a cada Sumo Pontífice eleito, uma vez que essa provém diretamente de Jesus Cristo. ${ }^{15}$ Trata-se, antes, de perquirir a respeito da causa agente da investidura no ofício papal.

13 Dialogus, III, I, IV, cap. XX, 865: "Christus qui ecclesiae suae in necessariis non deficit, ecclesiam suam non reliquit, nan habere caput est inter caetera maxime necessarium ecclesiae, ergo aliquod caput dedit ecclesiae, non autem instituit caput ecclesiam [...] secundum debiliorem [...] modum regiminis [...] ne facto videretur paecepisse, optimus autem modus regiminis est regiminis unius, ut unus omnes regat, quia talis modus regendi maxime principatui regali, qui est optimus secundum philosophos in hoc non errantes \& principatui paterno, qui est naturalis, assimilatur, ergo Christus unun caput dedit universalis ecclesiae \& non plura, non autem alium, quod Petrum [...]"; 866: "ipsam in optima conditione reliquit, quantum permittit haec vita".

14 Brevilóquio, ed. cit. Liv. IV, cap. 5: 137: "[...] De três modos se pode entender que alguma jurisdição provém de Deus. O primeiro modo refere-se àquela jurisdição que provém só de Deus [...] Assim também o bem-aventurado Pedro recebeu só de Deus o poder que lhe foi dado por aquelas palavras de Cristo: 'Apascenta minhas ovelhas' [...] também o poder episcopal é recebido daquele que consagra, mas não sem que haja antes eleição, pela qual [...] não é conferido o poder episcopal.

Deste modo parece a alguns que o poder papal provém só de Deus em todos os sumos pontifices após o bem-aventurado Pedro, porque embora Cristo, sem a ação ministerial do homem, tenha conferido a Pedro o poder pontificio, contudo de modo algum o confere a seus sucessores sem que haja eleição canônica [...]".

15 JOSÉ ANTONIO DE SOUZA, "Fundamentos eticos da teoria ockhamista acerca da origem do poder secular", Revista Portuguesa de Filosofia, 41 (1985):139-160, em particular: 148-160. 
Analisemos essa proposta de leitura do pensamento de Ockham relativa ao tema em apreço, por etapas. Comecemos tratando da origem do poder secular.

Os seres humanos em geral, caminheiros neste mundo, após a queda original, receberam de Deus, entre outros dons, a capacidade de escolher seus próprios dirigentes, (potestas instituendi rectores), porque necessitam de quem os lidere, a fim de que haja uma convivência pacífica, harmônica e ordenada entre eles, para que seus direitos individuais e sociais sejam resguardados.

Assim também, como Deus quis que os homens $O$ reencontrassem mediante a salvação que seu Filho trouxe a este mundo, tendo Ele instituído a Igreja na pessoa de seus Apóstolos para que ela continuasse a obra que Ele tinha inaugurado, ela, inserida neste mundo, não poderia ter uma organização interna que fosse inadequada à condição da presente vida humana.

Ora, a Igreja militante, compreendendo todos os batizados, clérigos e leigos, santos (a exceção) e pecadores (a regra), naturalmente necessita, portanto, à semelhança de qualquer outro povo, de alguém que a lidere visivelmente, a fim de que todos os seus membros possam ver atendidas suas necessidades espirituais e materiais. Esse alguém é o sucessor de Pedro, o Romano Pontífice, desde que eleito de acordo com as normas canônicas.

Destarte, como a Igreja tem uma causa eficiente ou fundamento secundário que opera cotidianamente no tempo e no espaço, isto é, seus dirigentes e todos os batizados, à frente dos quais está o sucessor de Pedro, assim também, conquanto todo poder político provenha de Deus, são os seres humanos que, vivendo em sociedade, através dos tempos e em lugares diferentes, escolhem de maneira efetiva os seus líderes políticos, adotando este ou aquele regime que lhes parece ser o melhor.

Semelhantemente, portanto, são os homens, ou melhor, determinadas pessoas competentes para tal, mediante a eleição pontifícia, que escolhem o Santo Padre, fundamento visivel e secundário da Igreja, conquanto não lhe confiram poder algum. A eleição papal, por conseguinte, é a melhor forma de se escolher alguém para ocupar o lugar de Pedro à frente da comunitas omnium fidelium, dado que os eleitores do Santo Padre têm a ocasiäo de optar pela pessoa mais apta para dirigila, de acordo com a necessidade e utilidade dum momento historicamente determinado. Por esse motivo, a Igreja, por exemplo, nunca permitiu que o Sumo Pontífice reinante viesse a designar o seu próprio sucessor.

Daí, sob o ponto de vista político, uma vez que a monarquia papal é eletiva e não hereditária, o poder jurisdicional (judicativo, legislativo e administrativo) do Sumo Pontífice absolutamente não pode ser tão amplo e ilimitado como o propunham os hierocratas. Também possui limites, estabelecidos quer pela Lei Evangélica, quer pela razão, isto é, por aquelas pessoas que através dos tempos, refletindo e escrevendo sobre o poder papal, impuseram-lhe determinados limites, os quais a Igreja igualmente acolheu, tanto quanto aquele outro ensinamento relativo ao primado. $^{16}$

16 Dialogus, III, I, IV, cap. XXII, 864: "[...] Desde o tempo dos Apóstolos até nossos dias, os prelados e doutores da Igreja, se sucedendo uns aos outros sem que houvesse descontinuidade, e os povos que lhes estavam submissos [...] sempre acreditaram convictamente que Pedro era superior aos demais Apóstolos [...]". 
Esta leitura política do pensamento de Ockham acerca do primado de Pedro só pode ser compreendida mediante uma outra idéia que ele expôs imediatamente antes, nos livros precedentes, a saber: caso aconteça, por exemplo, que um papa adira pertinazmente a uma heresia e tenha o apoio de um número considerável de pessoas, entre as quais, os cardeais, eleitores do Sumo Pontífice, os cristãos que vivem noutros lugares diferentes daquele em que o Sumo Pontífice mora ou das pessoas que aderiram a ele, que estejam racionalmente convictos daquele fato, podem livremente recusar a obedecer-lhe, e se thes parecer conveniente, escolherem ou não, em seu lugar um ou mais primazes que os liderem no plano eclesial e promovam o seu próprio bem estar espiritual, uma vez que este é o fim precípuo da Igreja.

Por esse motivo é que neste Livro IV, o Venerabilis Inceptor reitera que, na hipótese de uma evidente necessidade e desde que seja útil para todos os fiéis, estes podem modificar temporariamente o regime de governo da Igreja.

É preciso ressaltar, porém, que esses primazes não governariam a Igreja colegialmente, porque jamais Ockham admitiu essa hipótese. ${ }^{17}$

Entendemos que tal idéia fosse plausivel para o Venerabilis Inceptor não somente porque ele e seus companheiros de Munique e outras tantas pessoas que tinham aderido a eles, estivessem a enfrentar uma situação parecida, mas principalmente considerando que, se ele defendia o ponto de vista que os integrantes duma sociedade qualquer podiam, quando fosse útil ou necessário à mesma, mudar temporariamente seu regime político, ${ }^{18}$ adequando-o às circunstâncias, assim também, os batizados, usando a sua razão, integrantes da comunitas omnium fidelium, instaurada neste mundo, têm o direito de proceder da mesma maneira. ${ }^{19}$

Nossa interpretação ainda é corroborada por um outro passo do Livro II, desta $3^{a}$ parte do Dialogus em que o Menorita Inglês diz que, conquanto Cristo tenha estabelecido para a Igreja o regime monárquico de governo, todavia deixou também aos seus integrantes os direitos de indicar quem deve escolher seu dirigente supremo, quem deve assumir seu governo, isto é, uma ou muitas pessoas, quem deve corrigir tal pessoa se ela cometer certos delitos. ${ }^{20}$ Ora, esses procedimentos mostram de maneira evidente que a Igreja, ao menos em parte, é uma sociedade constituída pelos seres humanos e para eles próprios, semelhante à dos demais povos, o que, enfim, justifica e legitima de modo pleno a existência de um regime governa-

17 Dialogus, II, I, IV, cap. XXIII, 866: "Christus non praefecit apostolos aliis fidelibus tanquam collegium, sed tanquam singulares personas, dispergendi enim erant Apostoli universum orbem ad regendum fideles minime congregandi \& ideo tanquam collegium non regebant [...]".

18 Dialogus 817: "unaquaeque civitas et populus potest sibi ius proprium divina humanaque causa constituere [...] Ex quibus colligitur, quod quaelibet ecclesia et quilibet pobulus Christianus potest sibi auctoritate propria ius proprium statuere pro utilitate sua".

19 Dialogus, III, I, IV, cap. XXIV, 866: "melius est, ut ecclesia habeat potestatem mutandi modum regendi quandocunque expedit".

20 Dialogus, III, I, II, cap. XX, 806: "Christum ordinavit ipsum [principatum] debere esse in Ecclesiam, quantum ad multa tamen [principatus] videtur esse humanus. Nam ad homines pertinet ordinare, quis assumi debeat ad ipsum, et qui debent eligere, et qui debent assumptum corrigere, si correctione indigeat, et consimilia. Ergo consimiliter quantum ad hoc [principatus] erit humanus, quod per homines debeat ordinari, an unus tantummodo vel plures quando expediret ad talem debeant assumi principatum [...]". 
mental, ${ }^{21}$ fato esse que ainda implica na necessidade de haver um líder investido com determinados poderes para governá-la. Nota-se aí implicitamente um argumento metafísico sustentando a doutrina do primado de Pedro, aliás, compartilhado também pelos hierocratas, pois se a Igreja tem um corpo, deve igualmente possuir apenas uma cabeça, do contrário, ou seria imperfeita ou um monstro disforme.

Mas, continuemos a analisar a seqüência do pensamento de Ockham. Eliminada a causa que suscitou a mudança temporária do regime de governo eclesiástico, o efeito ou remédio deve também ser suspenso, quer dizer, todos os fiéis têm a obrigação de lutar por restabelecer o regime monárquico, porque o Senhor ao escolher Pedro como chefe supremo de sua Igreja, inferior a Paulo em sabedoria e a João em perfeição, simultaneamente ensinou de modo explícito que ela devia regularmente manter esse regime, e o respeito formal ao preceito positivo divino, nos impõe observá-lo non pro sempre. (Dialogus III, II, I, cap. VIII: 878).

Se por ventura um hierocrata objetasse essa idéia, afirmando que um certo número de primazes governando simultaneamente partes da Igreja espalhada pelo mundo prejudicaria sua unidade governamental e religiosa, bem como a sucessão apostólica, Ockham no Livro II já tinha igualmente respondido ao argumento, dizendo que a necessidade ou a utilidade dos fiéis os obriga a tomar certas medidas que racionalmente parecem as melhores, ainda que jamais vários patriarcas ou primazes tenham simultaneamente governado a Igreja (Dialogus, III, I, II, cap. XXVIII: 816-817).

E de novo, recorrendo à experiência alicerçada em fatos concretos e recentes, - Franciscano Inglês arremata sua argumentação dizendo que, entre a morte de um Papa e a eleição de um outro, o trono de Pedro fica vago, a Igreja continua sendo governanda e nem por isso há uma ruptura no tocante à unidade governamental e religiosa e uma quebra da sucessão apostólica. ${ }^{22}$

Aliás, naqueles dias, por causa de várias circunstâncias que não é necessário mencionar agora, a Sé Apostólica tinha estado vacante diversas vezes durante períodos longos, por exemplo, entre a morte de Nicolau V (1292) e a eleição de Celestino V (julho de 1294); entre o falecimento de Bento XI (1303) e a escolha de Clemente V (1305), entre a morte deste Pontifice (1314) e a eleição de João XXII (1316).

Em suma, Ockham ao refutar a teoria de Marsilio, de um lado, mantendo-se fiel às suas idéias filosófico-políticas, estava convicto de que não era preciso aceitar todos os argumentos que se invocavam a favor do primado de Pedro, muito menos todas as conclusões que eram inferidas deste fato, e que, por exemplo, sustentavam a teoria da Plenitudo Potestatis. De outro, ele acreditava firmemente que o

21 Dialogus, III, I, IV, 866: "Christus instituendo Petrum [...] facto docuit ecclesiam, quod optimum genus regendi, ut scilicet sit unum caput et rector omnium, debet omnino servare, si potest absque detrimento boni communis; praeficiendo autem non quemcunque unum, sed Petrum [...] innuit facto, quod non totaliter ecciesiam suam optimo generi obligavit: quin in casu manifestae necessitatis vel utilitatis posset illum modum regendi omittere vel mutare, nullum scilicet eligendo, vel eligendo plures si id communitati fidelium manifeste expediret [...]".

22 Dialogus: 810: "licet ex causa differre electionem summi pontificis. Igitur licet pro tempore constituere alios, qui gubement communitatem fidelium". 
primado é uma verdade de fé, confirmada pela crença da Igreja universal, ponto de vista esse que também externou noutras obras, ${ }^{23}$ de modo que as suas idéias que acabamos de analisar relativas a este assunto realmente expressam o seu pensamento coincidente com o do Magistério, o qual violentamente negado por Marsílio, exigiu dele uma resposta profunda à altura.

Por isso, o Menorita Inglês, filho de Francisco, conquanto admirasse o Estagirita, diferentemente de Marsilio, que propugnara uma nova teoria do Estado em que a Igreja tinha de se submeter completamente ao poder laico, a ponto de ele ter negado qualquer tipo de autoridade aos seus dirigentes, e em particular ao sucessor de Pedro, em sua própria esfera de ação, julgava que, para haver um relacionamento e uma convivência harmônica entre os poderes constituídos no interior da comunitas omnium fidelium bastava elaborar uma teoria eclesiológico-política em que, paralamente se reconhecesse a autoridade papal, decorrente do Primado de Pedro $^{24}$ e se restabelecessem os antigos limites para o exercício da mesma, dado que o Divino Mestre havia ensinado para todos os seus Apóstolos que o principatus apostolicus est ministrativus, non dominativus.

23 Cfr. OND, Opera Politica, vol. II, 1963, 93: 686: "[...] sed beatus Petrus non fuit vicarius Christi quantum ad officium regis temporais. Ergo nec Christus habuit officium regis temporalis; et per consequens regum Christi non fuit temporale, sed spirituale: quale regnum beato Petro commisit, cum dixit: Pasce oves meas, et prius promiserat dicens: Tibi dabo claves regnun caelonum $[\ldots]^{n}$ O. O. I, 7: 34.

24 A. S. MCGRADE, The Political Thought of William of Ockham, Cambridge University Press, Cambridge, 1974, 163: "In normal circumstances, then, Ockham's position on ecclesiastical govemment would be conservative in the sense of endorsing an undivided papal primacy ordinatione Christr". 